\title{
Synovial sarcoma
}

\begin{abstract}
Authors:
Sucari S.C. Vlok ${ }^{1}$

Georg W.W. Wagener ${ }^{1}$

Dan Zaharie²

Affiliations:

${ }^{1}$ Division of Radiodiagnosis, Stellenbosch University,

South Africa

${ }^{2}$ Department of Anatomical Pathology, Stellenbosch University, South Africa

Correspondence to:

Sucari Vlok

Email:

sucarivlok@gmail.com

Postal address:

11 Bergzicht, Wylant Street,

Welgemoed, Bellville 7530,

South Africa

Dates:

Received: 28 July 2014

Accepted: 13 Nov. 2014

Published: 12 Dec. 2014

How to cite this article:

Vlok, SSC, Wagenaar,

GWW, Zaharie, D. Synovial

sarcoma. S Afr J Rad.

2014;18(2); Art. \#704,

3 pages. http://dx.doi.

org/10.4102/sajr.v18i2.704

Copyright:

(C) 2014. The Authors.

Licensee: AOSIS

OpenJournals. This

work is licensed under

the Creative Commons

Attribution License.
\end{abstract}

\section{Read online:}

Synovial sarcoma is a malignant, predominantly juxta-articular, soft-tissue tumour representing approximately $10 \%$ of all soft-tissue sarcomas. Frequently initially incorrectly diagnosed as a benign lesion, it should be considered as a diagnosis when a young adult patient presents with a calcified juxta-articular soft-tissue mass of insidious onset.

\section{Introduction}

Synovial sarcoma was first reported in $1893^{1}$ and named after its microscopic resemblance to normal synovium. ${ }^{2}$ It is thought to originate from primitive mesenchymal cells that undergo differentiation to resemble synovial cells. ${ }^{2,3,4,5}$

Synovial sarcomas usually occur in adolescents and young adults, with no gender or racial predilection..$^{2,3,4}$ They typically affect the extremities (80\%-95\% of cases) ${ }_{1}^{4}$ arising from tendons, tendon sheets and bursal structures. It is important to note that they usually arise beyond the confines of the joint capsule. The single most commonly affected site is the knee. ${ }^{2,3,4,5,6}$

Synovial sarcomas are frequently initially incorrectly diagnosed as benign processes such as myositis, synovitis, haematoma, tendinitis or bursitis, ${ }^{2}$ resulting in the time to final diagnosis ranging from two to four years. ${ }^{4}$ It is therefore important to consider synovial sarcoma when a young adult patient presents with a calcified juxta-articular soft-tissue mass of insidious onset. $^{5}$

\section{Case report}

A 14-year-old boy presented at initial consultation with a one-year history of a tender, slowgrowing, juxta-articular left knee mass. Conventional radiographs revealed a soft-tissue mass with coarse calcifications (Figure 1). Magnetic resonance imaging (MRI) displayed a soft-tissue mass with heterogeneous T1 and T2 signal characteristics (Figure 2). An excision biopsy, followed by haematoxylin and eosin staining (Figure 3) and subsequent examinations, was performed in order to establish the diagnosis. The cells were positive for MNF (a pan-epithelial marker), EMA (epithelial membrane antigen), CD99 and bcl2. FISH (fluorescence in situ hybridisation) was positive, confirming the diagnosis of synovial sarcoma.

\section{Discussion}

Synovial sarcoma is a slow-growing, high-grade malignant neoplasm with extensive metastatic potential. ${ }^{4,5}$ It accounts for approximately $10 \%$ of all soft-tissue sarcomas ${ }^{3}$ and occurs predominantly in adolescents and young adults between the ages of 15 and 40 years. ${ }^{2,3,4,5}$

The extremities are affected in $95 \%$ of cases, and the lower limb in $70 \%$ of the former. ${ }^{6}$ The neoplasms usually occur in close proximity to large joints of the extremities, predominantly around the knee, ${ }^{2,3,4,5,6,7}$ followed by the ankle, elbow and shoulder. ${ }^{2}$ They rarely occur in the head, neck, thorax and abdomen. ${ }^{3}$

Synovial sarcomas are usually found in close association with tendon sheets, bursae and joint capsules, but joint involvement is rare. ${ }^{2}$ When intra-articular involvement does occur, it usually extends from an extra-articular site into the joint space. ${ }^{4,5}$

Patients most commonly present with insidious onset of a peri-articular, palpable, deep-seated swelling or mass that is commonly associated with pain or tenderness. ${ }^{2,3,4,5,6,7}$ The duration of symptoms varies from weeks to decades, with an average duration of $2-4$ years. ${ }^{2,3,4}$ 

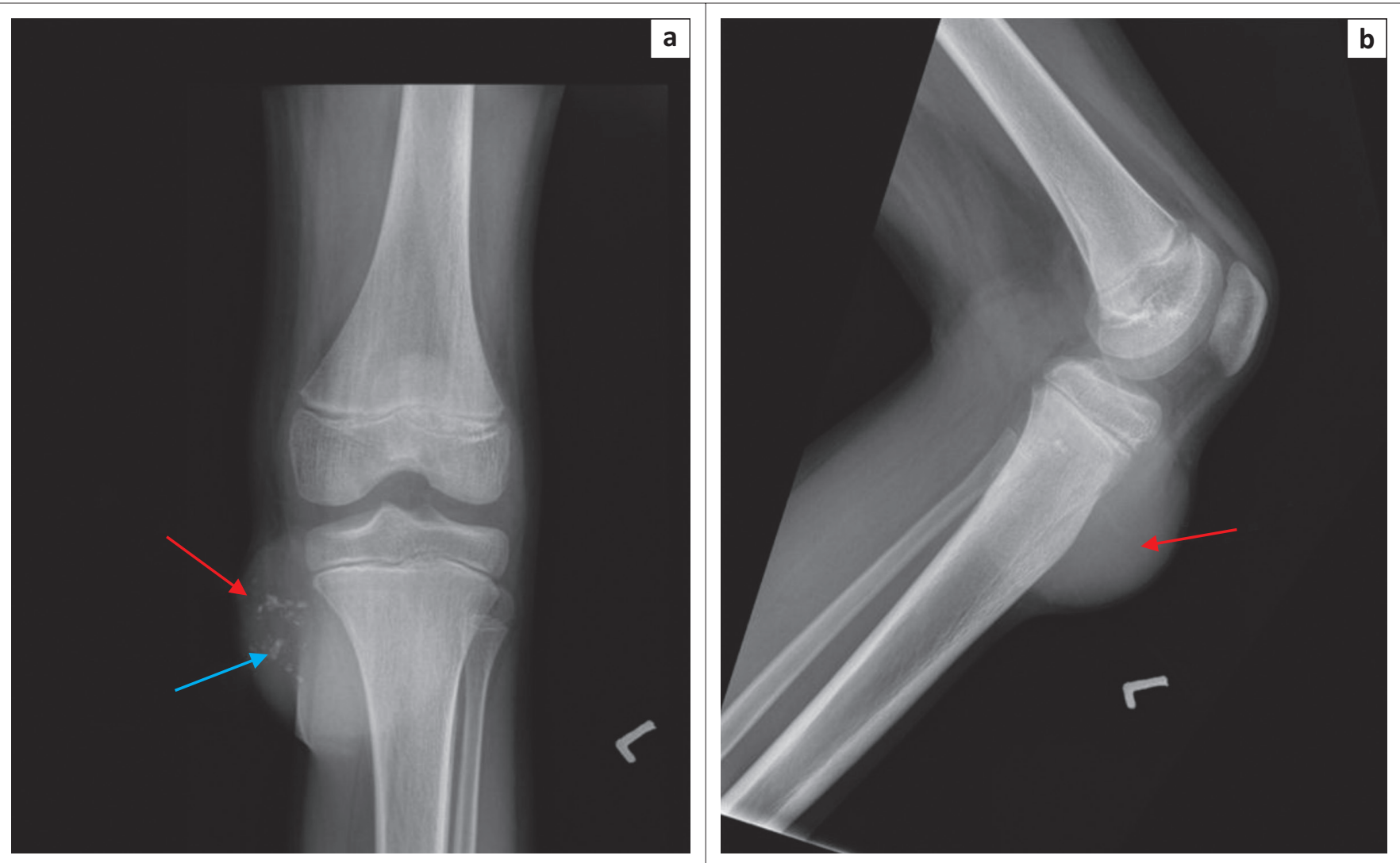

FIGURE 1: Anteroposterior (a) and lateral (b) radiographs of the left knee display a soft-tissue mass anteromedial to the proximal tibia (red arrows) of an adolescent patient. Note the coarse calcifications (blue arrow, AP view).

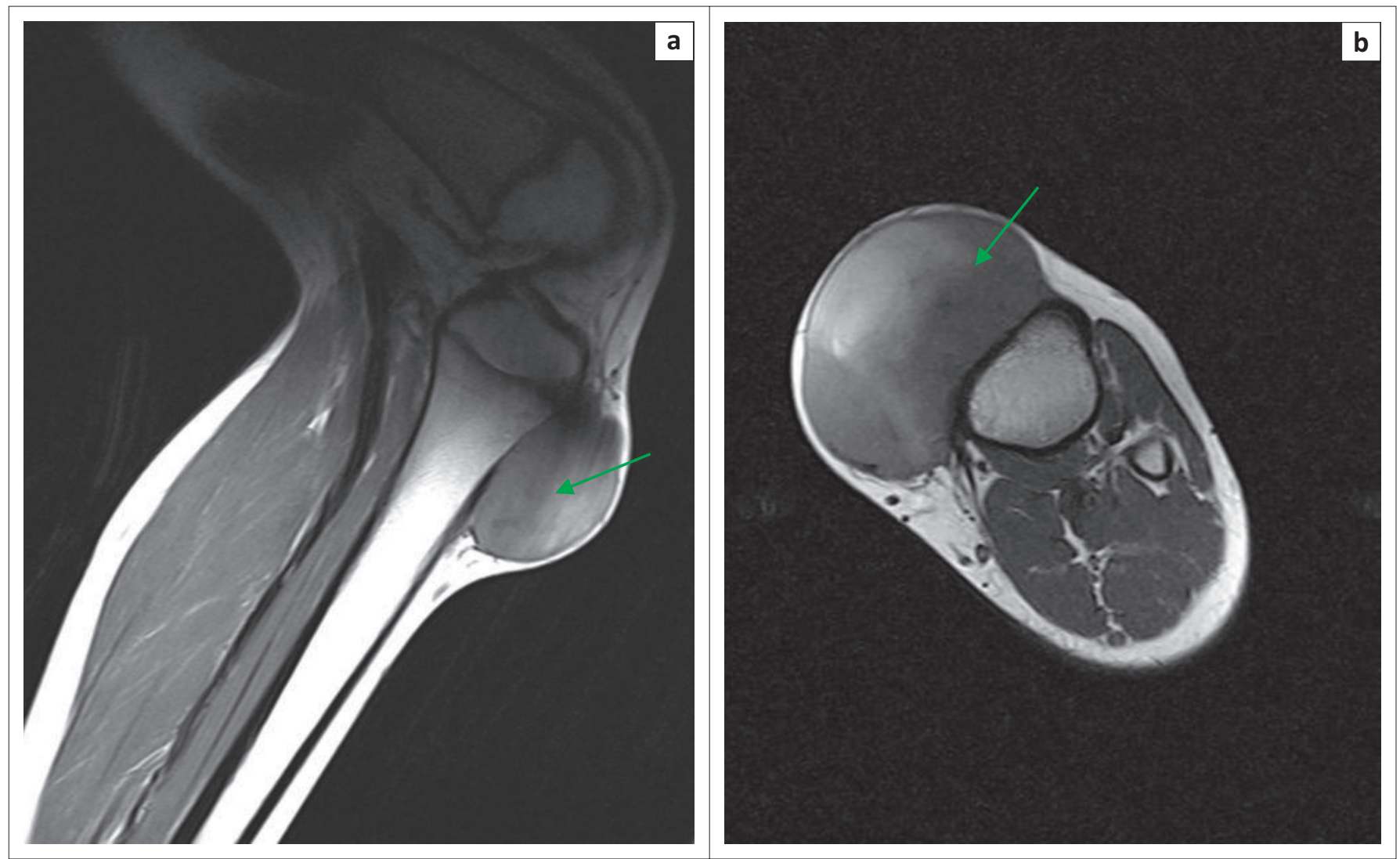

FIGURE 2: Sagittal (a) and axial (b) T1W images reveal mixed iso- and hyperintense changes within the soft-tissue mass (green arrows) owing to haemorrhage, without bony or subcutaneous fat involvement. 


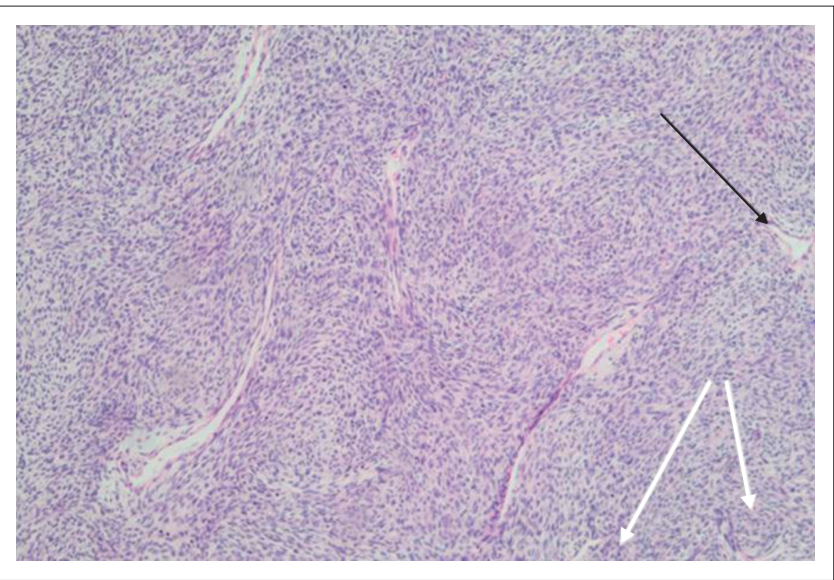

FIGURE 3: Haematoxylin and eosin staining, X 100 magnification. Overlapping spindle cells with scanty cytoplasm and hyperchromatic nuclei. Some of the cells formed small nests (white arrows) reminiscent of epithelial differentiation. Also present are stag horn blood vessels with a haemangiopericytic pattern (black arrow).

Metastases are present in a quarter of patients at initial diagnosis, ${ }^{5}$ and mainly affect the lungs ${ }^{2,3,4,5}$ and, to a lesser extent, lymph nodes, bone and rarely the liver or brain. ${ }^{3}$

Conventional radiographs may appear normal in approximately $50 \%$ of cases. ${ }^{4}$ Typical radiographic features include a juxta-articular soft-tissue mass within $5 \mathrm{~cm}$ of the joint and amorphous calcifications in $20 \%-30 \%$ of cases, which are often eccentric or peripheral. ${ }^{4}$ An associated periosteal reaction is present in $15 \%-20 \%$ of cases. ${ }^{2,3,4,5,6,7}$

Computed tomography (CT) scanning shows a soft-tissue mass with or without calcifications and bony involvement. $2,3,4,5,6,7$ MRI is reserved for local staging of the extent of the disease.

Characteristic changes include a heterogeneous, multilobulated soft-tissue mass with a signal intensity similar to or slightly higher than that of muscle on T1W, and a mixed high, intermediate, low signal on $\mathrm{T} 2 \mathrm{~W}$ that has been described as the triple sign. Fluid-fluid levels are seen in $25 \%$ of cases. . $^{2,3,4,5,6}$

Fluorodeoxyglucose positron emission tomography (FDGPET) is helpful in differentiating recurrent tumour from post-therapeutic changes, and is valuable in determining prognosis. ${ }^{3,7}$

It is important to note that imaging appearances are largely non-specific; biopsy is always necessary for the final diagnosis. At our institution, this is the domain of the clinician and not the radiologist. The current treatment of choice is surgery with or without radiotherapy. The use of chemotherapy is controversial. ${ }^{3,5}$

\section{Teaching point}

Synovial sarcoma features prominently in the differential diagnosis of a soft-tissue tumour around the knee in a young patient.

\section{Conclusion}

Synovial sarcoma represents approximately $10 \%$ of all softtissue sarcomas and must be considered in addition to other sarcomas when adolescents or young adults present with insidious onset of a calcified juxta-articular mass, especially around the knee.

\section{Acknowledgements Competing interests}

The authors declare that they have no financial or personal relationship(s) that may have inappropriately influenced them in writing this article.

\section{Author contributions}

Dr Wagener presented the case at the Musculoskeletal Imaging Congress held in Cape Town in February 2014. The report was written by Dr Vlok and reviewed by Dr Wagener. Histological images and legends were supplied by Dr Zaharie.

\section{References}

1. Craig RM, Pugh DG, Soule EH. The roentgenologic manifestations of synovial sarcoma. Radiology. 1955;65(6):837. http://dx.doi.org/10.1148/65.6.837

2. Siegel HJ, Sessions W, Casillas MA, Said-Al-Naief N, Lander PH, Lopez-Ben R. Synovial sarcoma: Clinicopathologic features, treatment and prognosis. Orthopedics. 2007;30(12):1020-1025.

3. Bakri $A$, Shinagare $A B$, Krajewski $K M$, et al. Synovial sarcoma: Imaging features of common and uncommon primary sites, metastatic patterns and treatment response. AJR. 2012;199(2):W208-W215. http://dx.doi.org/10.2214/ AJR.11.8039

4. Murphey MD, Gibson MS, Jennings BT, Crespo-Rodriguez AM, Fanburg-Smith J, Gajewski DA. Imaging of synovial sarcoma with radiologic-pathologic correlation. Radiographics. 2006;26(5):1543-1565.

5. Roberts CC. STATdx Premier. Synovial sarcoma. Salt Lake City: Amirsys; 2005-2014. [cited 10-30 May 2014]. Available from: http://my.statdx.com

6. O'Sullivan PJ, Harris AC, Munk PL. Radiological features of synovial cell sarcoma. $\mathrm{Br}$ J Radiol. 2008;81(964):346-356. http://dx.doi.org/10.1259/bjr/28335824

7. Dähnert W. Radiology Review manual. 6th ed. Philadelphia: Lippincott Williams \& Wilkins; 2007; p. 166-167. 